\title{
He Rāngai Maomao, He Iti Pioke: Te Mauri o Pūheke
}

Patukoraha and Te Whanau Moana, two northern hapū, have experienced severe language loss as evidenced by the depleting numbers of speakers of the reo in contexts such as marae, home, community events etc. A language revitalisation strategy is proposed as a way to support these hapū to reverse language shift and the decline of competent speakers and return the language to its appropriate and rightful place in the cultural and social domains as the essence of Māoritanga and integral component of cultural identity.

\section{Who am I?}

Patukoraha and Te Whānau Moana are two northern hapū or subtribes, with affiliations to the five major tribes inhabiting Te Hiku o te Ika, The Tail of the Fish, the far northern stretch of Aotearoa, New Zealand. My main tribe of affiliation is Ngāti Kahu, the descendants of Kahutianui, an ancestress who arrived on the Mamaru waka. The traditional boundaries of these two peoples stretch from the Awanui flats through to Te Rangi Aniwaniwa, across the Rangaunu harbour encircling the Karikari Peninsula and into Tokerau Moana or Doubtless Bay.

These people are traditionally seafaring people, living on, in, around and by the sea, hence the name Te Whānau Moana, The People of the Sea. Patukoraha are an offshoot of this hapū, and other hapū which diverge in history during local in-fighting, Patukoraha means to bludgeon into the wilderness, so named by the death of the chief Te Moho. 
I am a descendant of these chiefs, of these ancestors and bear their legacy. The legacy I bear is the retention, transmission and succession of my mother tongue, the language of my ancestors, so, their sayings, teachings, prayers, knowledge and customs can be passed down through the generations, and their lessons echoed through the ages.

I am a third generation urban born Māori. I was born in Tamaki Makaurau, Auckland City, into a whānau, family that first moved to the city with my great grandparents, as did the great majority of rural Māori in the decades of the 1930s to 1970s. In the 1930s there was about a 25\% shift of Māori to the cities, increasing to $75 \%$ by the 1970 s (Christensen, 2001). It is one of the largest and most intensive urban migrations recorded in history. Along with this migration came a whole range of culture shocks and culture loss which would become apparent in due course.

The Native Schools Act Created schools specifically for Māori, by the mid 1800s were exclusively taught in English, brutally punishing children that slipped back into their native tongue.

My great grandfather was the son of the first Māori head teacher of a Native School from 1902 to 1919. His appointment was a triumph, in so much as he was able to uphold his standing as a local chief in tribal dealings, and support the children's Māori language and identity, whilst delivering the "essential" education to the children and tribe via the Pākehā school system.

The loss of language was not so apparent at this time, but by the time these children grew to adulthood, the hard lessons learnt at the hand or whip of the school masters influenced them and the decision to speak Māori.

So my great grandfather grew up strong in his Māori mātauranga, knowledge, and tikanga, customs, also gaining his formal education to tertiary level, thus being appointed as a court scribe and translator and moving to Tamaki Makaurau. 
So this generation quickly learnt to follow the English education system to get ahead in the new and emerging world. Thus, my grandmother and her siblings were the first Māori students to attend the prestigious Pākehā grammar schools. As the example had been set, so this generation excelled in their environs of education, but there was a cost.

There was an unseen and, perhaps, an unintentional occurrence that happened between these two generations, i.e. the demise in the transmission of the mother tongue. It is as if that generation unconsciously decided to stop talking Māori to its children.

My grandmother could not speak Māori, nor could her siblings. My mother cannot speak Māori, nor can her siblings. My generation cannot speak Māori. Along with the loss of the language, we lost our customs, and our links to the marae, our tribal meeting complex. We also lost our identity, albeit, we knew we were from the north, and apart from the little observed customs we had left; we in essence were Pākehā.

My journey of rediscovery started when, whilst travelling through Europe I found that most people were multilingual; they had their native tongues plus at least one or two other major European languages.

It struck me as strange that there in Europe, I was learning languages from around the world, and yet my own mother tongue was so acutely absent. So upon arrival home, I immersed myself in the pursuit of my language, my mother tongue. So for the last 10 years I have been studying, learning, speaking and teaching Te Reo Māori.

Māori have a saying, "tōku reo tōku ohooho", "my language my awakening", and it is true, that Māori believe the reo lies latent inside, an intrinsic part of your being, awaiting to be activated. Once I leant my reo a whole new world was open to me, a whole new experience, a whole new me.

So the desire grew, to continue to learn, especially my own dialect, I started returning home, bolstering the relationships with my whanaunga, relations, of home and learning my own 
customs and dialect. But it was apparent that there was a severe lack of proficient speakers left; mostly being kaumātua, the older generation. So it was not long since firstly I was a fluent speaker, and secondly a male, before I was thrust into a position of service, standing as a speaker in helping to facilitate the cultural exchanges of my tribe. Although this was a challenge, and a very daunting experience because of the pressure that rewards andopportunities opened up to me as well as a whole new knowledge of my language and culture, of who I am.

This is where my desire to see te reo return to its rightful place originated, and when the opportunity arose to follow this path I am traversing now I took it with the firm belief that I can help bring about that change, for the betterment of my people. But firstly let us take a look at some statistics regarding the health and state of Te Reo Māori.

\section{Te Reo Māori}

\section{"Ko te reo te mauri o te mana Māori"}

This proverbial saying was left to us by one of my recent tupuna, Sir James Henare, a farmer, anointed warrior, decorated war veteran, repository of tribal lore, chief and elder statesman. He was a staunch supporter of, and believer in the language of his ancestors and in its upmost standing as a main pillar of his Maoritanga, cultural identity. His dedication made him as a stalwart, promoter and champion of this precious taonga, treasure.

In 1985, Sir James Henare stated this phrase during the Waitangi Tribunal's inquiry into te reo Maōi:

'The language is the core of our Māori culture and mana. Ko te reo te mauri o te mana Māori (The language is the life force of the mana Māori). If the language dies, as some predict, what do we have left to us? Then, I ask our own people who are we?' (in Durie 1998) 
This saying encapsulates the very essence of what language is, and what its loss could mean for the iwi. He is not alone in his view; his sentiments are echoed throughout the world. Indeed Fishman $(1997)^{1}$ says, '... ethnic language, ethnic identity and ethnic culture (behaviours, beliefs, artefacts) are all completely intertwined', 'without language the nation disappears'.

From Fishman to Henare, there is a common and indeed a very urgent and implicit need to act in preserving and transmitting the multitudes of languages across the globe. If the predictions are correct, about half the world's 6000 odd languages could be extinct within 100 years.

From the turn of the $20^{\text {th }}$ century there has been acute and intense decline in Māori language use and its domains. From an almost 90\% saturation level in the 1930s to an incredible $10 \%$ by 2000 . A major contributor to this, was the break in the intergenerational transmission of the language in the homes and communities.

Accompanying migration to urban centres, the people also lost their connection to their language and its value. The status of the dominant culture's language slowly and surely swelled, until a tidal wave of pressure and influence washed away the integral transmission lines, leaving but small, isolated islands surrounded by a sea of monolingual, urbanised and isolated people, adrift on the tides of colonisation.

This is evident in the statistics, which paint a grim picture, where within a rapidly growing population, the numbers of native speakers are ever waning, with very few native speakers in the parenting demographics. 


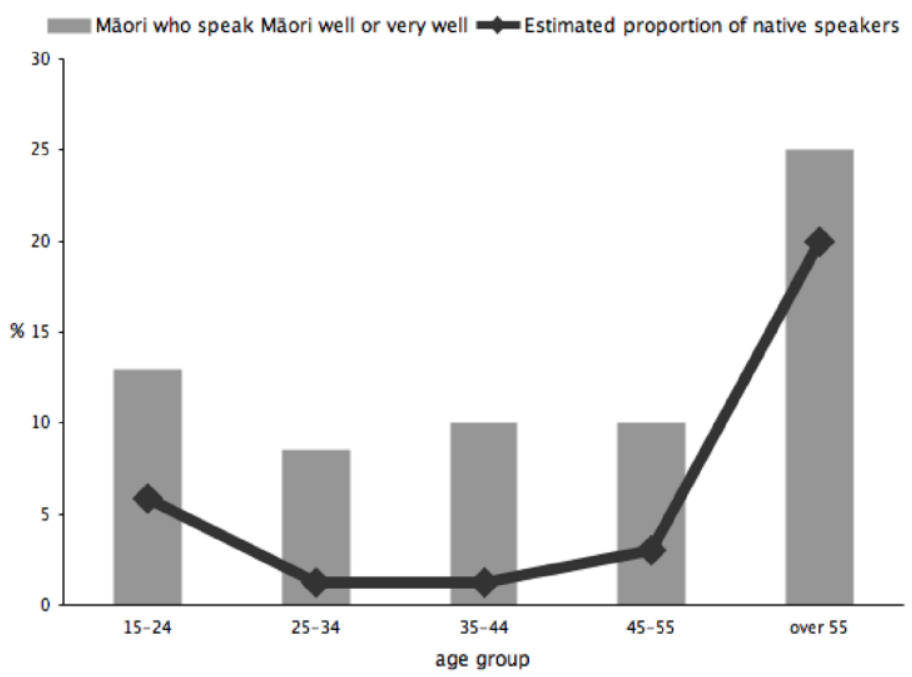

Source: Jeanette King (2009).

\section{Te Pū o te Wheke}

Pūheke is my sacred mountain, my ancestral mountain, a tribal boundary bordering both Patukoraha and Te Whānau Moana. Pūheke is the abbreviated version of his name, the full name is Te Pù o te Wheke, or The Head of the Octopus. When my tūpuna arrived, there was a giant wheke lying in the harbour blocking the entrance, so they recited their karakia, incantations, and charged it with the duties as a kaitiaki, guardian of the whānau, of the area. And so Pūheke stands sentinel, ever alert, ever watchful, and to this day, Puheke stands staunch and silent to the ever increasingly untrained ears of his iwi.

Being such an important and impressive feature of the landscape and being a sentinel, it was a natural choice as a framework by which the treasures of generations that he holds within his arms can be retained for the future descendants.

So the language is the head, the mouth, the identity of the hapu. Every arm has a cultural principle with the objective or 
function to feed the head. This is the Pū o te Wheke. Every arm moves independently of the others, but the head still controls them all, likewise the head is sustained by every arm. To borrow a Greek proverb, "One hand washes the other, both wash the face". The eloquence of this proverbial saying and all its richness, sums up the Pū o te Wheke and the co-dependent nature of all the functions ensure a harmonious and sustaining existence, therefore, allowing the wheke to adapt and survive.

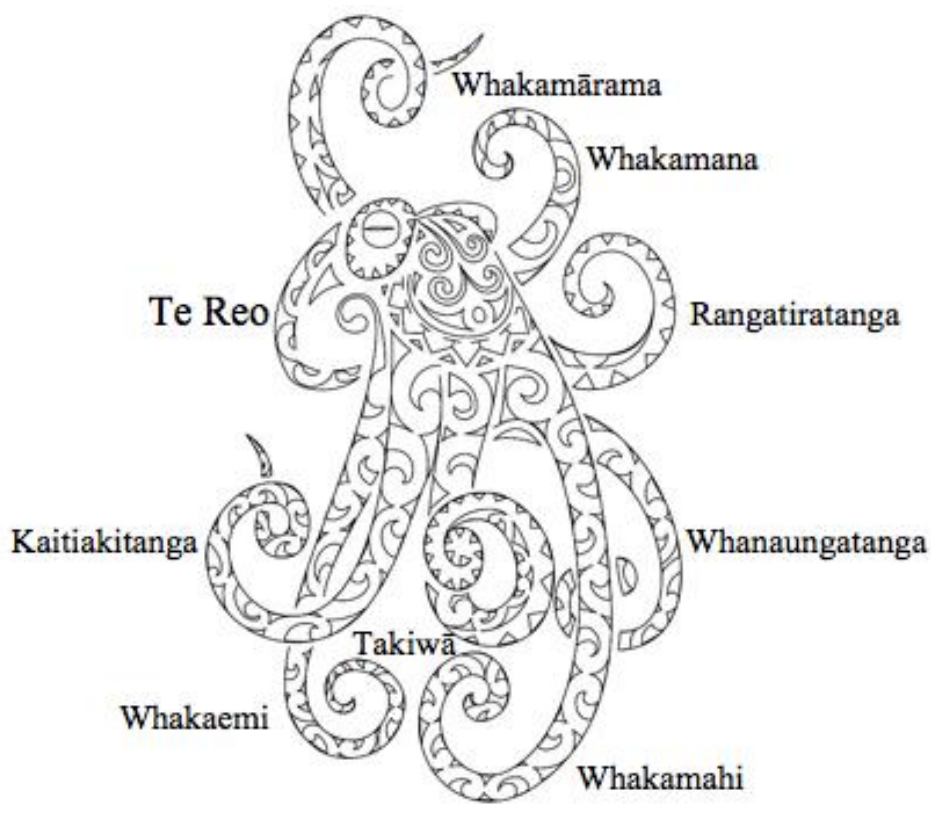




\section{Te Reo}

The head represents the language, the identity of the hapū, it is also the core of the strategy. There is a saying, "ko te reo te poutāwhā e iri ai ngā taonga katoa o rātou mā", "the language is the post/beam upon which all the treasures of the ancestors are adorned". The language is thus the vehicle through which all the cultural aspects of the people are carried and conveyed.

To remove it is like a house of cards, or, as Fishman puts it, a domino effect, if one falls it sets off a chain reaction, effecting change, and eventual shift through all the cultural markers.

Thus if you do not have your own language you cannot use...'traditional own-ethnicity-associated language for the purposes of ethnic self-definition and association'.

\section{Whakamārama}

Critical Awareness is an important function of any language strategy, an influencing and endorsing mechanism allowing distribution and dissemination of information pertaining to the language.

The main purpose of this arm, is to act as a vehicle delivering critical and pertinent discourse to the iwi. Many people do not know or understand what language is or what it means to culture. Critical awareness is an avenue that reaches people, explaining what role the reo plays in their cultural identity, what state the language is in, how, when, where and why it should be valued and retained.

In this day and age of technology, and demographic shift across vast distances, there is great scope for e-technologies, utilising mobile and internet applications to connect and communicate, teach and learn, research and document.

\section{Whakamana}

Status Planning may be one of the biggest challenges, examining the attitudes of the iwi to te reo, and analysing the standing of the reo within the community. Recent surveys 
show that (Ngaha, 2004), as the age of respondents lessens, so does the importance of te reo as a significant marker of cultural identity. In direct contrast to the statements from the likes of Henare, Fishman et al., language sits at the bottom as a cultural identity marker. Much like Fishman's allusion to the "xmen via yish" (have you a reference here?), the majority of the iwi are Māori via English.

One of the biggest challenges is to change the perception of the value of te reo, to endorse the cultural capital of te reo and encourage people to see the inherent value and benefit to having te reo.If the people do not see the value and importance of te reo, they will not buy into the language or any strategies to revitalise it.

\section{Whakamahi}

Application looks at the different ways of learning, teaching, and using the language within the community of the hapu The main focus of this strategy is the language in the homes and communities. Therefore, the strategy looks at methods to return the language to the main focal points of the community first and foremost and then look at the wider community.

There are already national strategies for children from preschool through to secondary school. There are also some limited options for language learning in the tertiary sector. The problems, or the real needs are firstly, the parent age and adult age population, secondly, the marae or tribal meeting house and thirdly, having other viable areas outside of these domains.

Methods that will be explored are marae-based studies involving the community in and on the tribal meeting house as a traditional learning centre, using wānanga or live -in hands on methodologies like tahi whenua, or walking the land to reclaim the names and histories of the area.

In home and in class, language learning programmes based upon Te Ataarangi, a full immersion method developed by Te Heikōkō Mataira and Ngoi Pewhairangi, based on 
Gattegno's 'The Silent Way' will be used. Also successful online learning systems such as those provided through $\mathrm{Te}$ Ipukarea, the National Language Institute located in AUT University will be utilised.

\section{Whakaemi}

Archiving is an essential tool in gathering, creating and storing valuable documentation of the language, of stories, sayings and histories to be used as taonga, as a pool of knowledge, to create resources for the hapū.

Interviewing surviving kaumātua, elders and collecting existing written material are a way of recording the language and establishing a corpus of words and discourse specific to Patukoraha and Te Whānau Moana.

\section{Rangatiratanga}

Management, as defined in this strategy rests solely with the hapu and the whānau. Rangatiratanga refers to the ability of the hapu to determine what is the appropriate application, establishing the most appropriater domains and facilitatinge the right people and their reo.

The main purpose of this strategy is to place within the hands of the hapu the mana, the authority to control the process, being free from bureaucratic processes from the hampering of top-down and heavy, policy-based national strategies, and from regional and even tribal politics. Fishman (1991) states:

...initial focusing on RLS-efforts per se is crucial, particularly on such efforts as can be engaged in by local communities and by their constituent families by means of their own efforts, resources and dedication. It councils greater sociocultural self-sufficiency, self-help, self-regulation and initiative... (Fishman, 1991, p. 4) 


\section{Whanaungatanga}

Community. The concept of whanaungatanga, or relations is paramount in Māori society. Everyone is connected and related. It is the belief that te reo is the thread that binds the whānau to whānau, the whānau to the hapū, the hapū to the iwi. In order to garner and promote intergenerational transmission it is essential to re-establish the kinship ties between the generations. As a result of urbanisation and migration, the hapū has been split, and the whānau are increasingly independent and isolated. The learning of the language I believe is a powerful vehicle in uniting the whanau and creating a cohesive and connected hapū.

It is essential to use our own whanaunga, relations, as kaiako, teachers, and mentors to the hapū, as facilitators and managers to run the strategy, and whānau as support, whilst re-connecting the hapū, it will also create language networks that can extend from the rural right through to urban settings.

\section{Kaitiakitanga}

Guardianship is an integral principle located in the belief that as Māori, we are but guardians of Mother Earth and all the treasures upon her. The land, the oceans, the forest are all treasures, and as the language sprung out of these, the language, and all that it encompasses, is a treasure of immense value; a treasure that has been passed down through the generations to us now, and we are charged with the responsibility to look after, and nurture this taonga for the following generations.

Sir Kingi Ihaka (1957, p. 42), another noted leader from the north, said "Ki te ngaro te reo Maori, Ki te ngaronga whenua Maori, - ka ngaro te mana Maori" "if the language is lost, if the land is lost then the Māori are lost". So an attitude of reverence has to be adopted to ensure that the responsibility be fostered amongst the hapu to see the value 
and importance and ultimately the continuation of this taonga.

\section{Takiwā}

Language domains that have been identified as primary domains such as the home, the marae, and other community interactive sites, such as sports, shops, etc. The home, being the major focus for language revitalisation efforts across the world, is often cited as the first step in the vitalisation of the reo, as Level 6 in the GIDS (Fishman, 1991) shows. If this scale is overlooked all other scales will not be fulfilled.

The marae, is the essential Māori domain, the last bastion of the reo, but really has succumbed to the sheer numbers of non- speakers, that Māori is now the language of ceremony, and upon completion English reigns supreme.

Like Fishman says, the home and intergenerational transmission are key to the survival of the language (Fishman 1991), he also emphatically states that it needs domains outside of the home, outside of the school, as domains for the language to find relevance and context in the wider world.

In summary, I refer back to the title of this research, He Rangai Maomao, He Iti Pioke. These sayings have been passed down through the generations carrying a myriad of instructions and information. The following two sayings in particular have great significance for my people, but also bare an important message of warning and encouragement.The first is a poroporoaki $\overline{1}$, a farewell paid to the departed spirits, 'he rāngai maoamo e taka atu ki tua o Nukutaurua, e kore a muri e hokia', ' a shoal of maoamo that passes beyond Nukutaurua, will never return'. Nukutaurua is a reef located in Tokerau harbour. A long time ago a famous chief, Tamatea left our area and travelled south, against the behest of the people to remain. He uttered these words, and with that departed never to return.And so it is with the language, it is a stark reminder, and should it pass beyond the point of no return, should it fall 
over the brink, it will not return, it will remain forever in the mouths of those who sleep in the silence of lost memories.

The second, 'he iti marangai tū ana te pāhukahuka, he iti pioke nō Rangaunu he au tōna', ' a small storm can make the seas stand in fury, in the wild tides of Rangaunu the small shark makes its own wake'. This proverb expresses the strength, courage and power that the small pioke has, even though it is but a small school shark, seeing it swim in the harbour it leaves its own wake.

Invoking this imagery and likening it to the language, even with the wild tides of the times, monolingualism, colonisation, globalisation; there is still hope to personify the qualities of the pioke. We shall swim against the tides creating a wake to be followed by our future generations; a path, a legacy left to us by our ancestors, to be nurtured, enhanced and passed on as a rich inheritance.

\section{Bibliography}

Christensen, I. (2001). Ko te whare whakamana: Māori language revitalisation. (Doctoral Thesis). Massey University, New Zealand.

Fishman, J. (1991). Reversing language shift: Theoretical and empirical foundations of assistance to threatened languages. Clevedon, England: Multilingual Matters.

Fishman, A. (1997). In Praise of the beloved language: A comparative view of positive Ethnolinguistic Consciousness. New York, NY: Mouton de Gruyter.

Henare, Sir James. In Durie, M. H. (1998). Te mana, te kawanatanga; the politics of Maori self-determination (pp57-59). Auckland, New Zealand: Auckland University Press.

Ihaka, K. (1957). Proverbial and popular sayings of the Maori: Nga whakatauki me nga pepeha Māori. Te Ao Hou 20, 42. Retrieved from

http://teaohou.natlib.govt.nz/journals/teaohou/issue/Mao20TeA /c21.html.

King, J. (2009). Language is life: The worldview of secondhand language speakers of Māori. In J. Reyhner \& L. Lockard (eds.). (2009). Indigenous Language Revitalization: Encourage- ment, Guidance \& Lessons Learned (pp. 97-108). Flagstaff, AZ: Northern 
Arizona University. $\quad$ Retrieved from http://jan.ucc.nau.edu/ jar/ILR/ILR-8.pdf.

Ngaha, A. (2005) Language and identity in the Māori community: Without the reo, who am I? In J. Holmes, M. MacLagan, P. Kerswill, M. Paviour-Smith (Eds), Researching language use and language users. Retrieved from http://www.nzlingsoc.org/documents/ngaha.pdf. 